\title{
Requirements of Larval Yellowtail for Eicosapentaenoic Acid, Docosahexaenoic Acid, and n-3 Highly Unsaturated Fatty Acid
}

\author{
Hirofumi Furuita, ${ }^{* 1, \dagger}$ Toshio Takeuchi, ${ }^{* 1}$ Takeshi Watanabe, ${ }^{* 1}$ \\ Hiroshi Fujimoto, ${ }^{* 2}$ Sachio Sekiya, ${ }^{* 2}$ and Keinosuke Imaizumi*2 \\ ${ }^{*}$ Department of Aquatic Biosciences, Tokyo University of Fisheries, \\ Konan, Minato, Tokyo 108, Japan \\ *2Japan Sea-Farming Association, Kamiura, Oita 879-26, Japan
}

(Received July 19, 1995)

\begin{abstract}
This study was conducted to investigate the requirements of larval yellowtail Seriola quinqueradia$t a$ for eicosapentaenoic acid (EPA), docosahexaenoic acid (DHA) and n-3 highly unsaturated fatty acid mixture (n-3 HUFA) by feeding them with Artemia nauplii containing different levels of these fatty acids or the mixture. Fish fed Artemia enriched with a low amount of n-3 HUFA showed low growth and survival, and poor vitality. These fish displayed swimming disorders such as spinning and disorientation. The best results were obtained in larvae fed on the nauplii containing 3.9\% n-3 HUFA (on dry matter basis). Elevation of DHA level in the nauplii improved survival, growth and vitality. Fish fed EPA showed poor vitality as low as those fed EFA deficient nauplii, although growth and survival were improved by supplement of EPA.

The requirement of larval yellowtail for n-3 HUFA is estimated to be about $3.9 \%$ (2.5\% EPA, $1.3 \%$ DHA and others) in Artemia on dry matter basis. The requirement for DHA is estimated to be $1.39-2.63 \%$ in Artemia on the basis of larval vitality. On the other hand, it is satisfied with $1.39 \%$ DHA ( $2.25 \% \mathrm{n}-3$ HUFA) or $3.65 \%$ EPA on the basis of survival rate.
\end{abstract}

Key words: essential fatty acid, EPA, DHA, n-3 HUFA, yellowtail, larvae

Yellowtail is one of the most important aquacultural fish in Japan. The recent development of mass propagation techniques has increased the production of juvenile fish to several millions. However, little information is available on the nutritional requirement of this species during larval stage. Newly hatched Artemia are being used frequently as a food for larval fish. A lack of $n-3$ highly unsaturated fatty acids (n-3 HUFA) which are essential fatty acids (EFA) for marine fishes was suggested for the reason why Artemia feeding results in poor survival and growth of larval fish. ${ }^{1)}$ Therefore, Artemia for larval yellowtail must always be enriched with oils containing high levels of n-3 HUFA. However, the requirement of larval yellowtail for n-3 HUFA is not yet clarified.

Recent investigations on requirement of marine fish for EFA have shown that docosahexaenoic acid (DHA) is superior to eicosapentaenoic acid (EPA) in providing better growth and vitality in larval fish such as flounder and red sea bream. ${ }^{2)}$ Quick reduction of DHA from eggs of these species also suggested difference of physiological function between EPA and DHA. ${ }^{3}$

This study was conducted to compare the EFA value between EPA and DHA for larval yellowtail, and determine the requirements of larvae for EPA, DHA and n-3 HUFA (a mixture of predominantly EPA and DHA) using Artemia nauplii enriched with different levels of these fatty acids.

\section{Materials and Methods}

Four experiments were designed in this study; Experiment I determined requirement of larval yellowtail for the n-3 HUFA mixture, Experiments II, III and IV compared EFA value between EPA and DHA, and determined requirements for both fatty acids.

\section{Feeding of Artemia}

Artemia nauplii with three different treatments were prepared in Experiment I. In Treatment no. 1, Artemia were non-enriched. In Treatment no. 2, Artemia were enriched with oil containing $42 \%$ n-3 HUFA mixture, prepared by mixing oleic acid methyl ester and a commercial Ester 85 (E85: n-3 HUFA mixture containing 34\% EPA, 38\% DHA and $3 \%$ other n-3 fatty acids, Nippon Chemical Feed Co. LTD.). In Treatment no. 3, Artemia were enriched with E85 and Marine alpha (Nisshin Fine Chemical Co. LTD.), a concentrate of socalled "marine Chlorella" containing $26.8 \%$ EPA. In other experiments, Artemia were enriched with ethyl ester type oils. In Experiment II, Artemia were enriched with oleic acid (OA, Treatment no. 4) or DHA (Treatment no. 5). In Experiments III and IV, three levels of DHA or EPA were prepared by mixing OA with EPA or DHA. Namely, OA (Treatment no. 6), 1/ 2DHA (OA:DHA=1:1, Treatment no. 7), DHA (Treat-

\footnotetext{
${ }^{\dagger}$ Present address: National Research Institute of Aquaculture, Nansei, Mie 516-01, Japan.
} 
Table 1. Rearing conditions for yellowtail in Expts. I-IV

\begin{tabular}{lcccc}
\hline & Expt. I & Expt. II & Expt. III & Expt. IV \\
\hline Fish size (mm) & $6.9 \pm 0.6^{*}$ & $7.1 \pm 0.6$ & $7.2 \pm 0.3$ & $7.0 \pm 0.5$ \\
Tank volume $(l)$ & 500 & 500 & 500 & 500 \\
Number of fish & 1000 & 1000 & 1000 & 1000 \\
Water tem-per-a-ture $\left({ }^{\circ} \mathrm{C}\right)$ & $21-23$ & $21-23$ & $22-24$ & $22-23$ \\
Water flow rate $(\mathrm{m} / / \mathrm{min})$ & $1000-1700$ & $350-1700$ & $350-1050$ & $350-1050$ \\
Air supply (ml/min) & 1000 & 1000 & 1000 & 1000 \\
Feeding fre-quency & 2 & 2 & 2 & 2 \\
$\quad$ (time/day) & & & & \\
Amount of food given & $24-120$ & $30-150$ & $30-150$ & $26-200$ \\
$\quad$ (x 104 nauplii/day) & 11 & 12 & 12 & 15 \\
$\begin{array}{l}\text { Experimental period (day) } \\
\text { lllumination (lux) }\end{array}$ & 1300 & 1300 & 1300 & 7000 \\
\hline
\end{tabular}

* Mean $\pm \operatorname{SD}(n=50)$

ment no. 8) in Experiment III, OA (Treatment no. 9), 1/ 2EPA (OA:EPA =1:1, Treatment no. 10), EPA (Treatment no. 11) in Experiment IV. The purities of OA, EPA and DHA were $95 \%, 99 \%$ and $99 \%$, respectively. EPA and DHA were purchased from Idemitsu Petrochemical Co. LTD. The procedures of treatments were described in the previous paper. ${ }^{4)}$

\section{Feeding of Larvae with Artemia}

Rearing conditions for fish in Experiments I-IV are shown in Table 1. The initial total length of fish was approximately $7 \mathrm{~mm}$ in all the experiments. The larvae had been reared with L-type rotifers fed on Nannochloropsis oculata and enriched with cuttlefish liver oil (Riken Vitamin Co. LTD.), and Artemia nauplii enriched with E85. Larvae were divided into 2 or 3 tanks; each group contained 1000 fish in a $500 l$ polycarbonate tank. They were fed one of the variety of enriched Artemia for 10-14 days. Illuminations on the surface of water in the tanks were 1300 lux in Experiments I-III, 7000 lux in Experiment IV. At the end of the feeding trials, an activity test, in which procedures were described in a previous paper, ${ }^{4)}$ was conducted to check the fish's response to the stress. The analytical procedures have been described in the previous papers.4-6)

\section{Results}

\section{Proximate and Fatty Acid Compositions of Artemia}

Figure 1 shows changes of n-3 HUFA contents in the nauplii during the feeding trial in Experiment $I$. The $n-3$ HUFA contents varied daily though nauplii from the same lot were enriched with the same lipids (n-3 HUFA in Artemia on dry matter basis: $0.6 \pm 0.35 \%, 2.4 \pm 1.00 \%$ and $3.9 \pm 1.43 \%$ in Treatment nos. 1,2 and 3 , respectively, $n=9$ ). Some factors, such as water temperature and activity of nauplii, might be concerned in the incorporation of n-3 HUFA by Artemia. Enrichment of Artemia needs care for these factors.

Table 2 shows proximate and fatty acid compositions of nauplii in Experiments III and IV. The EPA, DHA and n3 HUFA contents in nauplii used in Experiments I-IV are shown in Table 3. The lipid content was the highest in the EPA-Artemia. The concentration of EPA in the Artemia enriched with EPA was higher than that of the DHA at
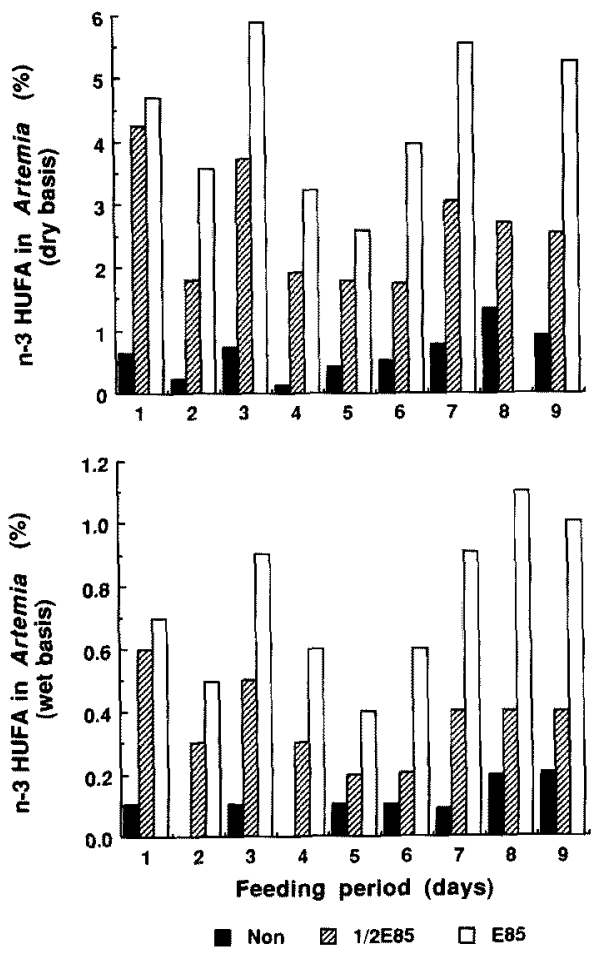

Fig. 1. Daily changes of n-3 HUFA content in Artemia (dry basis) during the feeding period in Expt. I.

any level of treatment. Retroconversion of DHA to EPA by Artemia was also observed (Table 2). These results were almost the same as previous study. ${ }^{4)}$

The contents of DHA and n-3 HUFA in Artemia (on dry matter basis) enriched with DHA were $1.39-2.63 \mathrm{~g} /$ $100 \mathrm{~g}$ and $2.25-4.09 \mathrm{~g} / 100 \mathrm{~g}$, respectively. The contents of EPA and n-3 HUFA in Artemia enriched with the various levels of EPA were $3.65-8.09 \mathrm{~g} / 100 \mathrm{~g}$ and $3.79-8.72 \mathrm{~g} /$ $100 \mathrm{~g}$, respectively.

\section{Growth, Survival, and Vitality of Larvae}

The results of the feeding experiments are shown in Figs. 2 and 3 and Table 3.

In Experiment I, fish (Tank no. 3) fed the E85-Artemia showed a higher mortality than other fish at the beginning of the experiment. This might be due to a shock of transportation to the experimental tank, because few fish died after that. In contrast, from the 8th day of feeding, fish of Tank nos. 2 and 3 began to die, resulted in low survival and growth. Most of these fish displayed swimming disorders (spin and disorientation), and showed poor vitality. Fish (Tank no. 3) fed Artemia containing a high amount of n-3 HUFA (Treatment no. 3) showed high survival, good growth and excellent vitality.

In Experiment II, fish received DHA (Tank no. 5) showed results better than those fed the OA-Artemia in survival, growth and vitality.

In Experiment III, fish (Tank no. 6) fed nauplii containing $0.8 \% \mathrm{n}-3$ HUFA showed low survival and growth together with poor vitality as observed in Experiments I and II. These fish showed also swimming disorders. Larvae fed nauplii enriched with $1 / 2 \mathrm{DHA}$ or DHA showed 
Table 2. Proximate and fatty acid compositions of total lipids (TL) in Artemia nauplii enriched with the experimental lipids ${ }^{*}$ in Expts. III and IV

\begin{tabular}{|c|c|c|c|c|c|c|c|c|}
\hline \multirow{3}{*}{ Fatty acid } & \multicolumn{4}{|c|}{ Expt. III } & \multicolumn{4}{|c|}{ Expt. IV } \\
\hline & \multirow[b]{2}{*}{ Initial } & \multicolumn{3}{|c|}{ Treatment no. } & \multirow[b]{2}{*}{ Initial } & \multicolumn{3}{|c|}{ Treatment no. } \\
\hline & & $\begin{array}{c}6 \\
\mathrm{OA}\end{array}$ & $\stackrel{7}{7}$ & $\begin{array}{c}8 \\
\text { DHA }\end{array}$ & & $\stackrel{9}{O A}$ & $\begin{array}{c}10 \\
1 / 2 \mathrm{EPA}\end{array}$ & $\begin{array}{c}11 \\
\mathrm{EPA}\end{array}$ \\
\hline $14: 0$ & 1.9 & $0.8 \pm 0.12^{* 2}$ & $0.7 \pm 0.05$ & $0.9 \pm 0.29$ & 0.9 & $0.7 \pm 0.05$ & $0.6 \pm 0.02$ & $0.6 \pm 0.04$ \\
\hline $16: 0$ & 11.6 & $8.6 \pm 0.57$ & $9.9 \pm 0.95$ & $11.9 \pm 0.53$ & 11.1 & $9.1 \pm 0.24$ & $8.9 \pm 0.33$ & $8.7 \pm 0.30$ \\
\hline $18: 0$ & 3.3 & $3.4 \pm 0.29$ & $3.5 \pm 0.05$ & $3.4 \pm 0.09$ & 3.7 & $3.4 \pm 0.24$ & $3.0 \pm 0.03$ & $3.0 \pm 0.28$ \\
\hline $18: 1 n-9$ & 13.7 & $36.6 \pm 1.96$ & $30.1 \pm 1.60$ & $14.5 \pm 0.21$ & & $410+242$ & $32.5+0.45$ & $18.7+0.77$ \\
\hline $18: 1 n-7$ & 5.9 & $5.2 \pm 0.96$ & $5.3 \pm 0.63$ & $5.5 \pm 0.25\}$ & 24.6 & $41.0 \pm 2.42$ & $32.5 \pm 0.45$ & $10.1 \pm 0.71$ \\
\hline $18: 2 n-6$ & 5.1 & $5.0 \pm 0.09$ & $4.5 \pm 0.12$ & $4.6 \pm 0.22$ & 5.9 & $5.3 \pm 0.06$ & $4.7 \pm 0.24$ & $4.1 \pm 0.14$ \\
\hline $18: 3 n-3$ & 30.0 & $20.5 \pm 1.39$ & $20.5 \pm 1.04$ & $25.0 \pm 0.42$ & 30.0 & $21.8 \pm 1.45$ & $21.2 \pm 0.40$ & $19.3 \pm 0.58$ \\
\hline $18: 4 n-3$ & 5.1 & $3.1 \pm 0.33$ & $2.8 \pm 0.12$ & $3.4 \pm 0.05$ & 5.2 & $3.4 \pm 0.33$ & $2.9 \pm 0.04$ & $2.7 \pm 0.03$ \\
\hline $20: 4 n-6$ & 0.4 & $0.3 \pm 0.05$ & $0.4 \pm 0.05$ & $0.4 \pm 0.05$ & 0.4 & $0.4 \pm 0.02$ & $0.2 \pm 0.02$ & $0.3 \pm 0.01$ \\
\hline $20: 5 n-3$ & 2.2 & $1.9 \pm 0.14$ & $3.4 \pm 0.21$ & $4.8 \pm 0.05$ & 2.4 & $2.1 \pm 0.08$ & $13.2 \pm 0.74$ & $29.3 \pm 1.20$ \\
\hline $22: 6 n-3$ & ND & ND & $5.9 \pm 0.66$ & $10.2 \pm 0.66$ & ND & ND & ND & ND \\
\hline$\Sigma n-6$ & 8.9 & $7.1 \pm 0.17$ & $6.6 \pm 0.17$ & $7.2 \pm 0.22$ & 8.3 & $7.2 \pm 0.12$ & $6.2 \pm 0.40$ & $5.5 \pm 0.17$ \\
\hline$\Sigma \mathrm{n}-3$ & 38.9 & $26.6 \pm 1.67$ & $33.2 \pm 1.09$ & $43.2 \pm 1.14$ & 39.3 & $28.6 \pm 1.75$ & $38.5 \pm 0.19$ & $52.5 \pm 1.43$ \\
\hline En-3 HUFA & 3.2 & $2.6 \pm 0.56$ & $9.6 \pm 0.86$ & $15.9 \pm 0.67$ & 3.5 & $3.0 \pm 0.10$ & $13.7 \pm 0.72$ & $30.8 \pm 1.25$ \\
\hline Moisture & 86.6 & $89.2 \pm 0.28$ & $89.0 \pm 0.27$ & $89.4 \pm 0.09$ & 87.1 & $89.6 \pm 0.30$ & $88.8 \pm 0.28$ & $89.1 \pm 0.40$ \\
\hline $\mathrm{TL}$ & 3.5 & $3.2 \pm 0.05$ & $3.3 \pm 0.08$ & $3.3 \pm 0.10$ & 3.8 & $3.5 \pm 0.13$ & $3.8 \pm 0.13$ & $4.0 \pm 0.15$ \\
\hline \multicolumn{9}{|l|}{ In dry basis } \\
\hline $\mathrm{TL}$ & 26.2 & $29.6 \pm 0.57$ & $30.1 \pm 0.86$ & $32.4 \pm 1.15$ & 29.5 & $33.6 \pm 0.57$ & $33.7 \pm 0.86$ & $36.3 \pm 1.26$ \\
\hline Polar lipids & 9.6 & $8.7 \pm 0.40$ & $9.0 \pm 0.57$ & $9.1 \pm 0.67$ & 10.5 & $10.1 \pm 0.40$ & $9.1 \pm 0.67$ & $9.4 \pm 0.67$ \\
\hline \multicolumn{9}{|c|}{ Absolute quantity in Artemia $(\mathrm{g} / 100 \mathrm{~g})$} \\
\hline $20: 5 n-3$ & 0.45 & $0.43 \pm 0.60$ & $0.79 \pm 0.80$ & $1.23 \pm 0.55$ & 0.53 & $0.50 \pm 0.08$ & $3.65 \pm 0.40$ & $8.09 \pm 1.13$ \\
\hline $22: 6 n-3$ & $\mathrm{ND}$ & ND & $1.39 \pm 0.92$ & $2.63 \pm 0.80$ & ND & ND & ND & ND \\
\hline n-3 HUFA & 0.65 & $0.59 \pm 0.65$ & $2.25 \pm 1.01$ & $4.09 \pm 0.89$ & 0.77 & $0.78 \pm 0.06$ & $3.79 \pm 0.61$ & $8.72 \pm 1.33$ \\
\hline
\end{tabular}

* OA, oleic acid ethyl ester (purity, $95 \%<$ ); DHA, docosahexaenoic acid ethyl ester (purity, $99 \%<$ ); EPA, eicosapentaenoic acid ethyl ester (purity, $99 \%<$ ).

${ }^{*}$ Mean $\pm \mathrm{SD}(n=3)$.

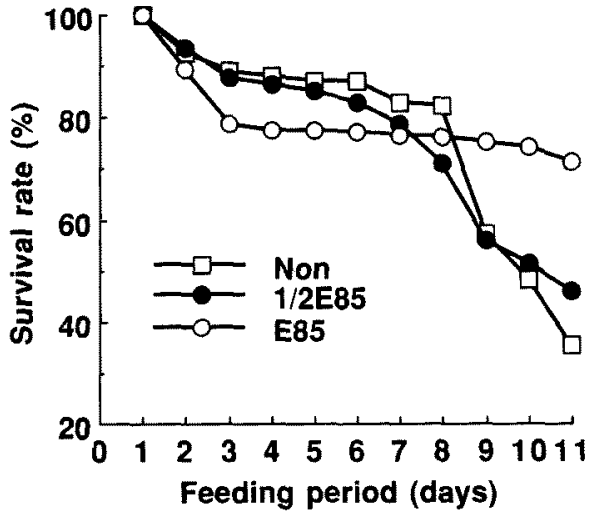

Fig. 2. Survival rate of larval yellowtail fed Artemia nauplii enriched with three levels of $n-3$ HUFA in Expt. $I$.

high survival rate. However, fish fed the DHA-Artemia showed better growth and vitality than that fed 1/2DHA.

In Experiment IV, there was little difference in survival before the 12th day of feeding, but fish fed OA showed higher mortality than others after 12 th day. Survival of fish fed OA was distinctly higher than those received the same treatment in Experiments II and III at the 12th day. Difference of illumination between the experiments might have an effect on fish. However, it is not clear which factor affected fish survival, since other conditions, such as fish, Artemia and etc., differed between the experiments. Growth was improved by elevation of EPA content in nauplii, but there was little difference in survival between fish fed 1/2EPA and EPA. Small fish fed EPA displayed swimming disorders.

\section{Lipid Classes and Fatty Acid Composition of Larvae}

Lipid contents and lipid classes of fish in Experiments II-IV are shown in Table 4. Lipid contents did not differ markedly between treatments. The contents of total and neutral lipids in fish fed OA or EPA were higher than those fed DHA, whereas fish fed DHA excelled others in polar lipid content.

Fatty acid compositions of larvae clearly reflected compositions of nauplii. In Experiment I, the 18:1 and 18:3n-3 levels increased, and DHA and n-3 HUFA decreased in total lipids (Table 5). In Experiments II-IV, larvae fed $A r$ temia containing low level of n-3 HUFA had a higher accumulation of OA, especially in neutral lipid. EPA or DHA levels especially in polar lipid increased proportionally to contents of these fatty acids in nauplii (Table 6).

N-3 HUFA in phosphatidylethanolamine (PE) were more abundant than phosphatidylcholine $(\mathrm{PC})$ in Experiments III and IV. DHA in PE was up to three times of PC, whereas difference in EPA was not so marked (Table 7). 
EXPT.III

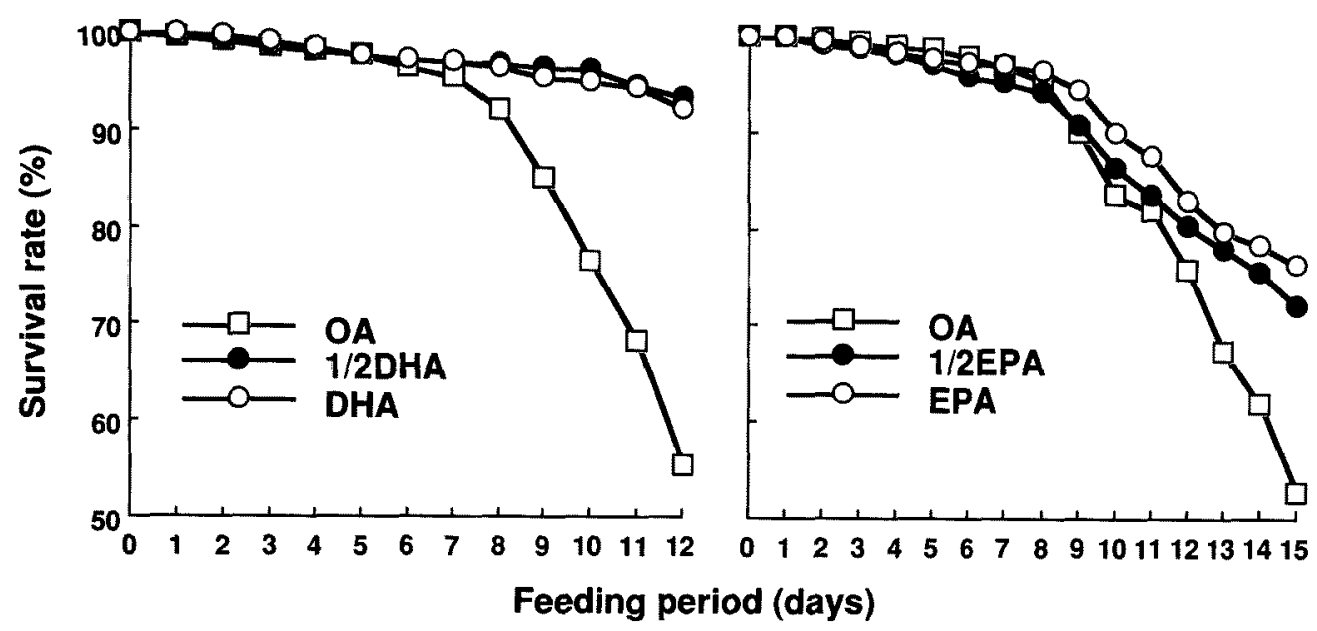

Fig. 3. Survival rate of larval yellowtail fed Artemia nauplii enriched with ethyl ester of OA, EPA and DHA in Expts. III and IV.

\section{Discussion}

Numerous studies have reported the importance of dietary $\mathrm{n}-3$ HUFA to improve survival of marine fish. ${ }^{3)}$ In this study, dietary value of Artemia was improved by elevation of n-3 HUFA content in nauplii in Experiment I. Survival was low $(35.5 \%$ ) when n-3 HUFA content was $0.6 \%$ and increased dramatically to $71 \%$ when n-3 HUFA content was $3.9 \%$. Growth and vitality were also improved by elevation of n-3 HUFA level in nauplii. Fish fed the highest level of n-3 HUFA did not display swimming disorders. However, n-3 HUFA and DHA levels in larvae fed Artemia containing 3.9\% n-3 HUFA decreased to half and one third of the initial value, respectively, and a high percentage of 18:1 in the fish was recognized as the same as larvae received the lowest level of $\mathbf{n}-\mathbf{3}$ HUFA. The ratio between 18:1 and n-3 HUFA, one of the EFA index proposed for larval red sea bream, and some marine fish larvae, increased to 2.27 from the initial value of 0.72 . This value was higher than those $(1.0>$ or $0.5>)$ in larvae, such as red sea bream, ${ }^{7,8)}$ flounder ${ }^{97}$ and gilthead seabream, ${ }^{10)}$ fed optimal levels of n-3 HUFA. This implied that the optimal n-3 HUFA level for larval yellowtail might be higher than $3.9 \%$ in Artemia. This might be supported by the fish fed more than 3.9\% n-3 HUFA which showed excellent vitality in Experiments II and III.

Nutritional value of DHA for larval yellowtail was already shown to be superior to EPA in other fish. ${ }^{2}$ In this study, survival was improved by supplement of EPA or DHA, but DHA was better than EPA in providing vitality (Fig. 3). Growth was improved by elevation of EPA or

Table 3. Growth, survival and vitality of yellowtail after 11-, 12-, 12- and 15-day feeding trials in Expts. I-IV

\begin{tabular}{|c|c|c|c|c|c|c|c|}
\hline \multirow{2}{*}{ Tank no. } & \multicolumn{3}{|c|}{ In $A$ rtemia (dry wt. $\%$ ) ${ }^{*_{1}}$} & \multirow{2}{*}{$\begin{array}{l}\text { Final total } \\
\text { length }(\mathrm{mm})\end{array}$} & \multirow{2}{*}{$\begin{array}{l}\text { Survival } \\
\text { rate(\%) }\end{array}$} & \multicolumn{2}{|c|}{ Vitality $(\%)^{* 2}$} \\
\hline & EPA & DNA & n-3HUFA & & & $30 \mathrm{~s}$ & $1 \mathrm{~min}$ \\
\hline \multicolumn{8}{|l|}{ Expt. I } \\
\hline 1 (Non) & 0.4 & ND & 0.6 & $11.0 \pm 1.9^{\mathrm{a}^{* 3}}$ & 35.5 & 22 & $-^{*_{4}}$ \\
\hline $2\left(1 / 2 \mathrm{E} 85^{* 5}\right)$ & 1.4 & 0.8 & 2.4 & $13.0 \pm 2.8^{b}$ & 46.1 & 32 & - \\
\hline $3(\mathrm{E} 85)$ & 2.3 & 1.3 & 3.9 & $14.1 \pm 2.3^{\mathrm{c}}$ & 71.3 & 86 & - \\
\hline \multicolumn{8}{|l|}{ Expt. II } \\
\hline $4(\mathrm{OA})$ & 0.7 & ND & 0.8 & $13.7 \pm 3.1^{\mathrm{a}}$ & 48.7 & 8 & $2^{* 6}$ \\
\hline 5 (DHA) & 1.8 & 4.6 & 6.7 & $17.2 \pm 2.9^{\mathrm{b}}$ & 81.7 & 94 & $56^{*} 6$ \\
\hline \multicolumn{8}{|l|}{ Expt. III } \\
\hline $6(\mathrm{OA})$ & 0.6 & ND & 0.8 & $13.9 \pm 2.5^{\mathrm{a}}$ & 55.1 & 6 & 0 \\
\hline $7(1 / 2 \mathrm{DHA})$ & 1.0 & 1.8 & 2.9 & $15.7 \pm 2.2^{b}$ & 93.4 & 32 & 20 \\
\hline 8 (DNA) & 1.6 & 3.3 & 5.2 & $17.6 \pm 2.1^{\mathrm{c}}$ & 91.5 & 84 & 75 \\
\hline \multicolumn{8}{|l|}{ Expt. IV } \\
\hline $9(\mathrm{OA})$ & 0.7 & ND & 1.0 & $14.2 \pm 2.4^{\mathrm{a}}$ & 52.9 & 6 & 4 \\
\hline $10(1 / 2 \mathrm{EPA})$ & 4.5 & ND & 4.6 & $16.1 \pm 3.8^{b}$ & 72.2 & 4 & 0 \\
\hline 11 (EPA) & 10.6 & ND & 11.2 & $18.8 \pm 2.7^{\mathrm{c}}$ & 76.5 & 6 & 0 \\
\hline
\end{tabular}

*I (Lipid $\% \times$ dry wt. $x$ area $\%$ of each fatty acid) $\times 100$.

* Survival rate at activity test. Number of fish, 50 .

*3 The values not sharing a common superscript letter are significantly different at $p<0.05$. Number of fish, 50 .

$* 4$, Not tested.

${ }^{* 5}$ E85, methyl esters containing more than $85 \%$ of $n-3$ HUFA.

*6 2 min. 
Table 4. Lipid content and classes*i of yellowtail fed Artemia nauplii enriched with the experimental lipids in Expts. II, III and IV

\begin{tabular}{|c|c|c|c|c|c|c|c|c|c|c|c|}
\hline \multirow[b]{3}{*}{ Initial } & \multicolumn{3}{|c|}{ Expt. II } & \multicolumn{4}{|c|}{ Expt. III } & \multicolumn{4}{|c|}{ Expt. IV } \\
\hline & & \multicolumn{2}{|c|}{ Tank no. } & \multirow[b]{2}{*}{ Initial } & \multicolumn{3}{|c|}{ Tank no. } & \multirow[b]{2}{*}{ Initial } & \multicolumn{3}{|c|}{ Tank no. } \\
\hline & & $\begin{array}{c}4 \\
\mathrm{OA}\end{array}$ & $\stackrel{5}{\text { DHA }}$ & & $\stackrel{6}{\mathrm{OA}}$ & $1 / 2 \mathrm{DHA}^{7} \mathrm{HA}$ & $\begin{array}{c}8 \\
\text { DHA }\end{array}$ & & $\stackrel{9}{O A}$ & 100 & $\begin{array}{c}11 \\
\text { EPA }\end{array}$ \\
\hline Moisture & 85.2 & 81.0 & 81.7 & 84.2 & 81.6 & 82.4 & 82.4 & 84.1 & 82.4 & 81.5 & 81.7 \\
\hline Total lipid (TL) & 3.3 & 3.7 & 3.1 & 3.0 & 3.4 & 3.0 & 2.8 & 2.5 & 3.2 & 3.2 & 3.4 \\
\hline $\mathrm{TL}$ & 22.5 & 19.6 & 16.9 & 19.0 & 18.5 & 16.9 & 16.1 & 15.8 & 18.2 & 17.0 & 18.5 \\
\hline Neutral lipids & 9.6 & 11.8 & 8.1 & 8.9 & 11.7 & 8.6 & 7.9 & 6.4 & 12.0 & 9.8 & 11.7 \\
\hline SE & 0.4 & 0.2 & 0.1 & 0.2 & 0.1 & 0.1 & 0.1 & 0.3 & 0.2 & 0.2 & 0.1 \\
\hline TG & 1.7 & 8.5 & 3.6 & 2.0 & 8.0 & 4.3 & 3.8 & 0.2 & 8.4 & 5.6 & 7.9 \\
\hline FFA & 3.4 & 1.3 & 1.3 & 2.5 & 1.5 & 1.2 & 1.4 & 1.6 & 2.1 & 1.8 & 1.7 \\
\hline $\mathrm{FS}$ & 3.7 & 1.4 & 2.5 & 3.7 & 1.9 & 2.1 & 2.5 & 3.6 & 2.1 & 1.6 & 1.5 \\
\hline $\mathrm{DC}$ & 0.3 & 0.2 & 0.2 & 0.3 & 0.3 & 0.2 & 0.2 & 0.1 & 0.5 & 0.3 & 0.3 \\
\hline $\mathrm{MG}$ & 0.2 & 0.1 & 0.3 & 0.3 & 0.2 & 0.1 & 0.1 & $\operatorname{tr}$ & 0.1 & 0.2 & 0.1 \\
\hline $\mathrm{PE}^{* 2}$ & 3.7 & 2.4 & 3.1 & 1.5 & 0.9 & 1.7 & 1.9 & 2.4 & 1.6 & 2.4 & 2.1 \\
\hline $\mathrm{PC}$ & 8.6 & 5.1 & 5.3 & 7.7 & 5.3 & 6.2 & 6.0 & 6.5 & 4.0 & 4.1 & 4.4 \\
\hline Sph & 0.2 & 0.1 & 0.2 & 0.1 & 0.1 & 0.1 & 0.2 & 0.1 & 0.2 & 0.1 & 0.2 \\
\hline LPC & 0.4 & 0.2 & 0.1 & 0.1 & 0.2 & 0.1 & 0.1 & 0.1 & 0.2 & 0.1 & 0.1 \\
\hline
\end{tabular}

${ }^{*}$ Abbreviations: SE, sterol esters; TG, triglycerides; FFA, free fatty acids; FS, free sterols; DC, diglycerides; MG, monoglycerides; PE, phosphatidylethanolamine; PC, phosphatidylcholine; Sph, sphingomyeline; LPC, lysophosphatidylcholine.

*2 Phosphatidylinositol and phosphatidylserine are included.

Table 5. Fatty acid composition of total lipids in larval yellowtail fed Artemia nauplii enriched with the experimental lipids in Expt. I

\begin{tabular}{|c|c|c|c|c|}
\hline \multirow[b]{2}{*}{ Fatty acid } & \multirow[b]{2}{*}{ Initial } & \multicolumn{3}{|c|}{ Tank no. } \\
\hline & & $\begin{array}{c}1 \\
\text { Non }\end{array}$ & $\frac{2}{1 / 2 \mathrm{E} 85}$ & $\begin{array}{c}3 \\
\text { E85 }\end{array}$ \\
\hline $14: 0$ & 1.1 & 0.6 & 0.6 & 0.7 \\
\hline $16: 0$ & 22.9 & 15.4 & 12.2 & 13.4 \\
\hline $16: \ln -7$ & 5.6 & 3.9 & 3.8 & 3.7 \\
\hline $16: 3 n-3$ & 1.0 & 0.9 & 0.5 & 0.6 \\
\hline $18: 0$ & 11.3 & 6.8 & 6.5 & 7.3 \\
\hline $18: \ln -9$ & $12.4\}$ & \multirow{2}{*}{28.0} & \multirow{2}{*}{33.2} & \multirow{2}{*}{28.2} \\
\hline $18: 1 \mathrm{n}-7$ & $5.2\}$ & & & \\
\hline $18: 2 n-6$ & 2.6 & 8.2 & 6.3 & 6.1 \\
\hline $18: 3 n-3$ & 1.7 & 13.8 & 16.5 & 16.0 \\
\hline $20: 4 n-6$ & 5.4 & 2.2 & 1.2 & 1.6 \\
\hline $20: 5 n-3$ & 8.6 & 5.1 & 5.3 & 6.7 \\
\hline $22: 5 n-3$ & 5.4 & 0.8 & 0.9 & 1.2 \\
\hline $22: 6 n-3$ & 10.1 & 1.4 & 2.5 & 3.6 \\
\hline Monoenes & 13.0 & 28.2 & 33.5 & 28.5 \\
\hline$n-3$ & 9.6 & 11.7 & 8.7 & 9.0 \\
\hline$n-6$ & 26.4 & 22.9 & 27.6 & 30.0 \\
\hline n-3 HUFA & 24.4 & 8.3 & 9.6 & 12.4 \\
\hline 18:1/n-3 HUFA & 0.72 & 3.37 & 3.46 & 2.27 \\
\hline
\end{tabular}

DHA level in nauplii, little difference between both fatty acids. Fish fed EPA showed swimming disorders and poor vitality, whereas disordered swimming was prevented by DHA and fish fed DHA showed excellent vitality. In larval red sea bream, EPA effectively improved fish survival as well as DHA, but was not able to improve fish vitality ${ }^{4,11)}$ and completely prevent hydrops. ${ }^{11)}$ DHA seems to be necessary for vitality of larvae, though the effects of dietary
EPA or DHA on larvae differ among species.

Recently, it was showed that the ratio of 18:1/DHA of polar lipid in larval red sea bream reflected EFA deficiency on the basis of larval vitality. ${ }^{4)}$ This ratio may also be used as the EFA index for larval yellowtail. A ratio of $18: 1 /$ DHA in polar lipid in larval yellowtail was less than 1 in the fish showing excellent vitality, and was higher than 1 in the fish showing poor vitality. However, availability of this value for evaluation of EFA status of yellowtail should be discussed after further accumulation of data on EFA requirement.

PC and PE were major phospholipid groups in the larval yellowtail like other species. ${ }^{12)}$ Their levels in fish were independent of food although their compositions were markedly influenced by n-3 HUFA contents in the nauplii. ${ }^{13)}$

The PE fraction contained higher n-3 HUFA, especially DHA, than PC fraction. Higher incorporation of EFA was also shown in the PE of cultured cells of turbot ${ }^{14)}$ and rainbow trout. ${ }^{15)}$ Increased level of n-3 HUFA of PE in fish fed DHA was higher than those fed EPA. This was mainly due to the selective incorporation of DHA into PE fraction as observed in turbot, ${ }^{14)}$ rainbow trout, ${ }^{15)}$ gilthead seabream ${ }^{16}$ and Atlantic herring. ${ }^{17)}$ It is already known that the molecular species composition of di-docosahexaenoyl was markedly higher in the PE than other phospholipids in cod brain and retina. ${ }^{18)}$ Kanazawa ${ }^{19)}$ suggested that depletion of DHA reduced visual ability and resulted in occurrence of abnormal pigmentation in flounder. It is supposed that DHA is important for larval yellowtail to develop their brain and retina since they depend on eyes and brain to identify, hunt and capture live prey. This is supported by selective incorporation of $\left[1-{ }^{14} \mathrm{C}\right] \mathrm{DHA}$ into brain and retina in larval yellowtail. ${ }^{* 3}$ Furthermore, high

\footnotetext{
${ }_{3}^{*}$ R. Masuda, T. Takeuchi, H. Sato, K. Shimizu, K. Imaizumi, and K. Tsukamoto: Abst. Metg. Japan. Soc. Fisheries Sci., April, 1995 , p. 42 (in Japanese).
} 
Table 6. Fatty acid compositions of neutral lipids (NL) and polar lipids (PL) in larval yellowtail fed Artemia nauplii enriched with the experimental lipids in Expts. II, III and IV

\begin{tabular}{|c|c|c|c|c|c|c|c|c|c|c|c|c|c|c|c|c|c|c|c|c|c|c|}
\hline \multirow{4}{*}{ Fatty acid } & \multicolumn{6}{|c|}{ Expt. II } & \multicolumn{8}{|c|}{ Expt. III } & \multicolumn{8}{|c|}{ Expt. IV } \\
\hline & \multirow{2}{*}{\multicolumn{2}{|c|}{ Initial }} & \multicolumn{4}{|c|}{ Tank no. } & \multirow{2}{*}{\multicolumn{2}{|c|}{ Initial }} & \multicolumn{6}{|c|}{ Tank no. } & \multirow{2}{*}{\multicolumn{2}{|c|}{ Intital }} & \multicolumn{6}{|c|}{ Tank no. } \\
\hline & & & \multicolumn{2}{|c|}{$\begin{array}{c}4 \\
O A\end{array}$} & \multicolumn{2}{|c|}{$\begin{array}{c}5 \\
\text { DHA }\end{array}$} & & & \multicolumn{2}{|c|}{$\stackrel{6}{\mathrm{OA}}$} & \multicolumn{2}{|c|}{$\begin{array}{c}7 \\
1 / 2 \mathrm{DHA}\end{array}$} & \multicolumn{2}{|c|}{$\begin{array}{c}8 \\
\text { DHA }\end{array}$} & & & \multicolumn{2}{|c|}{$\begin{array}{c}9 \\
\mathrm{OA}\end{array}$} & \multicolumn{2}{|c|}{$\begin{array}{c}10 \\
1 / 2 \mathrm{EPA}\end{array}$} & \multicolumn{2}{|c|}{$\begin{array}{c}11 \\
\mathrm{EPA}\end{array}$} \\
\hline & NL & PL & NL & PL & NL & PL & NL & PL & NL & PL & NL & PL & NL & PL & NL & PL & NL & PL & NL & PL & NL & PL \\
\hline $14: 0$ & 3.9 & 0.9 & 0.8 & 0.3 & 1.4 & 0.3 & 1.7 & 0.7 & 0.5 & 0.3 & 0.7 & 0.2 & 0.8 & 0.3 & 0.7 & 0.5 & 0.5 & 0.2 & 0.5 & 0.2 & 0.5 & 0.2 \\
\hline $16: 0$ & 14.1 & 21.1 & 9.7 & 14.9 & 10.7 & 16.9 & 11.5 & 19.1 & 8.8 & 13.5 & 9.3 & 14.6 & 9.3 & 16.7 & 9.0 & 21.0 & 8.3 & 14.3 & 8.2 & 15.2 & 8.0 & 15.6 \\
\hline $16: \ln -7$ & 17.9 & 5.5 & 2.6 & 1.2 & 3.4 & 1.1 & 11.2 & 3.8 & 4.1 & 2.1 & 3.9 & 2.0 & 4.4 & 2.0 & 4.2 & 3.1 & 3.6 & 2.0 & 3.3 & 1.7 & 3.2 & 1.5 \\
\hline $16: 3 n-3$ & 0.1 & 1.9 & 0.1 & 1.4 & 0.3 & 1.2 & 0.6 & 1.8 & 0.2 & 1.6 & 0.2 & 1.5 & 0.4 & 1.6 & 0.5 & 2.5 & 0.2 & 2.0 & 0.3 & 1.9 & 0.3 & 1.9 \\
\hline 18:0 & 2.8 & 9.3 & 3.7 & 8.9 & 2.4 & 10.1 & 5.1 & 8.6 & 4.3 & 8.7 & 4.6 & 9.5 & 4.3 & 10.0 & 4.5 & 10.1 & 3.7 & 9.3 & 4.2 & 10.3 & 3.8 & 11.5 \\
\hline $\begin{array}{l}18: \ln -9 \\
18: \ln -7\end{array}$ & $\begin{array}{r}12.4 \\
2.8\end{array}$ & $\begin{array}{r}12.9 \\
4.5\end{array}$ & $\begin{array}{r}36.7 \\
6.5\end{array}$ & $\begin{array}{r}25.5 \\
6.3\end{array}$ & $\begin{array}{r}17.0 \\
5.9\end{array}$ & $\begin{array}{r}13.8 \\
6.4\end{array}$ & $\begin{array}{r}12.6 \\
3.6\end{array}$ & $\begin{array}{r}11.3 \\
3.8\end{array}$ & $\begin{array}{r}36.5 \\
6.6\end{array}$ & $\begin{array}{r}24.8 \\
6.4\end{array}$ & $\begin{array}{r}30.7 \\
6.6\end{array}$ & $\begin{array}{r}18.8 \\
6.0\end{array}$ & $\begin{array}{r}17.8 \\
7.2\end{array}$ & $\left.\begin{array}{r}12.8 \\
6.9\end{array}\right\}$ & 15.6 & 16.2 & 46.8 & 31.9 & 38.6 & 29.0 & 25.7 & 20.7 \\
\hline $18: 2 n-6$ & 4.3 & 2.1 & 5.9 & 6.4 & 6.5 & 3.3 & 6.5 & 3.8 & 5.7 & 5.9 & 5.6 & 4.2 & 6.0 & 3.6 & 4.6 & 3.9 & 6.4 & 6.8 & 5.7 & 4.0 & 5.5 & 3.0 \\
\hline $18: 3 n-3$ & 2.0 & 0.3 & 17.9 & 10.4 & 24.7 & 5.9 & 3.0 & 1.0 & 18.3 & 10.8 & 17.7 & 7.4 & 22.8 & 6.8 & 4.7 & 1.8 & 16.3 & 9.4 & 17.6 & 7.0 & 18.6 & 5.8 \\
\hline $20: 4 n-6$ & 3.8 & 4.6 & 0.8 & 2.6 & 0.8 & 1.6 & 4.2 & 4.8 & 0.8 & 2.7 & 1.1 & 2.3 & 1.0 & 1.9 & 5.7 & 4.3 & 0.8 & 2.2 & 0.6 & 1.3 & 0.6 & 1.1 \\
\hline $20: 5 n-3$ & 14.0 & 9.5 & 2.8 & 9.0 & 5.8 & 6.3 & 13.8 & 10.6 & 2.6 & 7.4 & 3.4 & 7.1 & 4.9 & 6.6 & 13.1 & 8.7 & 2.4 & 7.0 & 9.6 & 18.5 & 20.4 & 23.4 \\
\hline $22: 5 n-3$ & 2.4 & 4.2 & 0.2 & 1.4 & 0.5 & 1.3 & 4.1 & 5.5 & 0.5 & 1.7 & 0.5 & 1.6 & 0.6 & 1.4 & 4.2 & 3.7 & 0.2 & 1.1 & 0.6 & 2.6 & 1.0 & 3.9 \\
\hline $22: 6 n-3$ & 8.7 & 11.9 & 0.3 & 1.8 & 7.2 & 23.7 & 11.4 & 13.8 & 0.6 & 2.0 & 4.3 & 14.9 & 7.8 & 20.0 & 15.1 & 13.7 & 0.3 & 1.8 & 0.2 & 1.1 & 0.2 & 1.3 \\
\hline Monoenes & 34.6 & 24.3 & 49.6 & 34.8 & 28.7 & 22.7 & 30.6 & 21.1 & 48.5 & 34.3 & 42.1 & 27.7 & 30.4 & 22.7 & 21.1 & 20.6 & 51.4 & 34.7 & 43.2 & 28.3 & 28.9 & 22.7 \\
\hline$\Sigma \mathrm{n}-6$ & 9.8 & 8.5 & 8.4 & 10.8 & 9.5 & 6.1 & 12.4 & 9.8 & 8.7 & 10.5 & 9.0 & 7.7 & 9.5 & 6.8 & 13.6 & 10.0 & 8.8 & 10.5 & 7.6 & 6.7 & 8.0 & 5.5 \\
\hline$\Sigma \mathrm{n}-3$ & 28.8 & 28.3 & 23.7 & 26.0 & 41.8 & 39.5 & 34.3 & 33.5 & 25.4 & 26.0 & 29.3 & 34.2 & 40.3 & 37.8 & 39.2 & 31.2 & 22.2 & 23.4 & 31.1 & 32.6 & 44.0 & 37.6 \\
\hline$\Sigma \mathrm{n}-3$ HUFA & 25.9 & 26.0 & 4.3 & 13.5 & 14.6 & 32.1 & 30.5 & 30.6 & 5.0 & 12.6 & 9.4 & 24.7 & 14.7 & 29.0 & 33.3 & 26.8 & 4.0 & 11.4 & 11.6 & 23.2 & 22.8 & 29.5 \\
\hline 18:1/n-3 HUFA & $-^{*}$ & 0.6 & - & 2.4 & - & 0.6 & - & 0.5 & - & 2.5 & - & 1.0 & - & 0.7 & - & 0.6 & - & 2.8 & - & 1.3 & - & 0.7 \\
\hline $18: 1 / 22: 6 n-3$ & - & 1.4 & - & 17.7 & - & 0.9 & - & 1.1 & - & 15.6 & - & 1.7 & - & 1.0 & - & 1.2 & - & 17.7 & - & 26.4 & - & 15.9 \\
\hline
\end{tabular}

* -, not calculated. 
Table 7. Fatty acid compositions of phosphatidylcholine (PC) and phosphatidylethanolamine (PE) in larval yellowtail fed $A$ rtemia nauplii enriched with the experimental lipids in Expts. III and IV

(area \%)

\begin{tabular}{|c|c|c|c|c|c|c|c|c|c|c|c|c|c|c|c|c|}
\hline \multirow{4}{*}{ Fatty acid } & \multicolumn{8}{|c|}{ Expt. III } & \multicolumn{8}{|c|}{ Expt. IV } \\
\hline & \multirow{2}{*}{\multicolumn{2}{|c|}{ Initial }} & \multicolumn{6}{|c|}{ Tank no. } & & & \multicolumn{6}{|c|}{ Tank no. } \\
\hline & & & \multicolumn{2}{|c|}{$\begin{array}{c}6 \\
\text { OA }\end{array}$} & \multicolumn{2}{|c|}{$\stackrel{7}{1 / 2 \mathrm{DHA}}$} & \multicolumn{2}{|c|}{$\stackrel{8}{\text { DHA }}$} & \multicolumn{2}{|c|}{ Initial } & \multicolumn{2}{|c|}{$\mathrm{O}^{9}$} & \multicolumn{2}{|c|}{$\begin{array}{c}10 \\
1 / 2 \mathrm{EPA}\end{array}$} & \multicolumn{2}{|c|}{$\begin{array}{c}11 \\
\mathrm{EPA}\end{array}$} \\
\hline & $\mathrm{PC}$ & $\mathrm{PE}$ & $\mathrm{PC}$ & $\mathrm{PE}$ & $\mathrm{PC}$ & $\mathrm{PE}$ & $\mathrm{PC}$ & PE & $\mathrm{PC}$ & $\mathrm{PE}$ & $\mathrm{PC}$ & $\mathrm{PE}$ & PC & PE & $\mathrm{PC}$ & $\mathrm{PE}$ \\
\hline $14: 0$ & 0.8 & 0.1 & 0.4 & 0.2 & 0.3 & 0.2 & 0.5 & 0.4 & 0.8 & 0.5 & 0.3 & 0.5 & 0.2 & 0.7 & 0.3 & 0.3 \\
\hline $16: \ln -7$ & 5.1 & 3.1 & 1.1 & 1.4 & 2.3 & 0.8 & 2.6 & 1.0 & 4.6 & 0.9 & 2.7 & 1.5 & 2.3 & 1.5 & 1.9 & 1.3 \\
\hline $16: 3 n-3$ & 0.4 & 3.6 & 0.3 & 4.6 & 0.2 & 4.0 & 0.3 & 3.8 & 0.6 & 7.5 & 0.3 & 6.0 & 0.3 & 4.7 & 1.6 & 5.4 \\
\hline $18: 0$ & 6.6 & 12.3 & 7.9 & 17.5 & 8.7 & 11.5 & 9.1 & 12.6 & 7.8 & 11.3 & 7.4 & 10.7 & 8,6 & 14.5 & 10.0 & 14.9 \\
\hline $18: 1 n-9$ & 14.9 & 7.5 & 28.9 & 15.0 & 21.9 & 9.1 & 15.0 & $5.8)$ & 200 & 180 & 372 & 198 & 250 & 151 & 250 & \\
\hline $18: \ln -7$ & 2.9 & 4.0 & 5.7 & 5.5 & 5.4 & 5.3 & 5.8 & $5.3\}$ & 20.0 & 18.0 & 51.2 & 19.8 & 20.0 & 15.1 & 25.9 & 10.1 \\
\hline $18: 2 n-6$ & 4.5 & 1.1 & 6.3 & 4.2 & 4.6 & 2.0 & 3.8 & 1.4 & 4.7 & 1.6 & 7.0 & 5.1 & 3.5 & 2.0 & 3.7 & 2.2 \\
\hline $18: 3 n-3$ & 1.2 & 0.5 & 11.8 & 7.0 & 8.2 & 3.3 & 7.3 & 2.3 & 2.2 & 0.6 & 9.0 & 6.7 & 6.5 & 3.4 & 6.4 & 3.7 \\
\hline $20: 5 n-3$ & 11.4 & 9.0 & 4.9 & 16.3 & 6.8 & 8.9 & 7.0 & 5.8 & 7.9 & 8.3 & 1.6 & 13.9 & 16.9 & 23.8 & 17.6 & 26.9 \\
\hline $22: 5 n-3$ & 4.0 & 8.2 & 0.7 & 4.9 & 1.3 & 3.4 & 1.2 & 2.6 & 2.2 & 6.1 & 0.4 & 2.3 & 1.7 & 4.7 & 2.9 & 4.7 \\
\hline $22: 6 n-3$ & 8.2 & 25.3 & 1.0 & 5.9 & 10.5 & 30.2 & 16.0 & 38.3 & 6.0 & 24.5 & 0.3 & 3.5 & 0.4 & 1.2 & 0.9 & 2.0 \\
\hline Monoenes & 25.6 & 16.4 & 36.9 & 23.4 & 30.4 & 16.1 & 24.3 & 13.2 & 30.5 & 21.6 & 40.5 & 27.3 & 27.8 & 17.8 & 28.4 & 18.0 \\
\hline$\Sigma n-6$ & 9.7 & 8.4 & 10.4 & 11.0 & 9.1 & 5.6 & 7.9 & 4.2 & 10.1 & 4.2 & 9.9 & 13.6 & 6.1 & 5.5 & 6.2 & 6.8 \\
\hline$\sum n-3$ & 26.0 & 47.4 & 21.1 & 40.9 & 28.7 & 51.0 & 33.2 & 53.9 & 19.5 & 44.1 & 12.9 & 34.7 & 27.1 & 38.6 & 30.7 & 43.9 \\
\hline$\Sigma \mathrm{n}-3$ HUFA & 24.2 & 43.1 & 7.9 & 29.0 & 19.5 & 43.8 & 25.0 & 47.7 & 16.5 & 39.8 & 3.0 & 21.5 & 19.7 & 30.3 & 22.2 & 34.6 \\
\hline
\end{tabular}

concentration of DHA in PE fraction might be concerned in fish vitality.

The present results have shown that the requirement of larval yellowtail for n-3 HUFA is estimated to be about $3.9 \%$ in Artemia on dry matter basis. The requirement for DHA is estimated to be $1.39-2.63 \%(2.25-4.09 \% \mathrm{n}-3$ HUFA) in Artemia on dry matter basis on the basis of vitality of larvae, and it is satisfied with $1.39 \%$ DHA ( $2.25 \%$ n-3 HUFA) on the basis of survival rate. On the other hand, the requirement for EPA is supposed to be satisfied with $3.65 \%$ (3.79\% n-3 HUFA) in nauplii on the basis of survival rate, so that EFA value of EPA is considerably inferior to DHA. It is important to take care of contents of n-3 HUFA and DHA in food for larval yellowtail to enhance the mass propagation of this species, since the requirements of this species for n-3 HUFA or DHA are higher than any other larvae so far studied.")

Acknowledgments We express our sincere gratitude to Mr. Yukiyasu Niwa and Mr. Masanori Toyota, Tokyo University of Fisheries, for their help in feeding experiments. This work was supported in part by a consignment research fund from the Fisheries Agency and by a Grant in Aid for Scientific Research from the Ministry of Education, Science, Sport and Culture.

\section{References}

1) T. Watanabe, F. Oowa, C. Kitajima, and S. Fujita: Relationship between dietary value of brine shrimp Artemia salina and their content of n-3 highly unsaturated fatty acids. Nippon Suisan Gakkaishi, 46, 35-41 (1980).

2) T. Watanabe: Importance of docosahexaenoic acid in marine larval fish. J. World Aquacult. Soc., 24, 152-161 (1993).

3) T. Takeuchi: Variety of essential fatty acids requirement in fish. Kagaku to Seibutsu, 29, 571-580 (1991) (in Japanese).

4) H. Furuita, T. Takeuchi, M. Toyota, and T. Watanabe: EPA and DHA requirements in early juvenile red sea bream using HUFA en- riched Artemia nauplii. Fisheries Sci., 62, 246-251 (1996).

5) T. Watanabe, T. Takeuchi, T. Arakawa, K. Imaizumi, and S. Sekiya: Requirement of juvenile striped jack Longirostris delicatissimus for n-3 highly unsaturated fatty acids. Nippon Suisan Gakkaishi, 55, 1111-1117 (1989).

6) T. Takeuchi, S.-J. Kang, and T. Watanabe: Effects of environmental salinity on lipid classes and fatty acid composition in gills of Atlantic salmon, Nippon Suisan Gakkaishi, 55, 1395-1405 (1989).

7) M. S. Izquierdo, T. Watanabe, T. Takeuchi, T. Arakawa, and C Kitajima: Requirement of larval red seabream Pagrus major for essential fatty acids. Nippon Suisan Gakkaishi, 55, 859-867 (1989).

8) M. S. Izquierdo, T. Watanabe, T. Takeuchi, T. Arakawa, and C. Kitajima: Optimal EFA levels in Artemia to meet the EFA requirements of red seabream (Pagrus major). Proc. Third Intn. Symp. on Feeding and Nutr. in Fish Toba Aug. 28 Sept. 1, Japan, 1989, pp. 221-232.

9) M. S. Izquierdo, T. Arakawa, T. Takeuchi, R. Haroun, and T. Watanabe: Effect of n-3 HUFA levels in Artemia on growth of larval Japanese flounder (Paralichthys olivaceus). Aquaculture, 105, 73-82 (1992).

10) W. M. Koven, A. Tandler, G. W. Kissil, and D. Sklan: The importance of n-3 highly unsaturated fatty acids for larval Sparts aurato and their effect on survival, lipid composition and size distribution. Aquaculture, 104, 91-104 (1992).

11) T. Watanabe, M. S. Izquierdo, T. Takeuchi, S. Satoh, and C. Kitajima: Comparison between eicosapentaenoic and docosahexaenoic acids in terms of essential fatty acid efficacy in larval red seabream. Nippon Suisan Gakkaishi, 55, 1635-1640 (1989).

12) S. Teshima, A. Kanazawa, K. Horinouchi, S. Yamasaki, and H. Hirata: Phospholipids of the rotifer, prawn and larval fish. Nippon Suisan Gakkaishi, 53, 609-615 (1987).

13) T. Watanabe: Lipid nutrition in fish. Comp. Biochem. Physiol. 73B, 3-15 (1982)

14) D. R. Tocher and E. E. Mackinlay: Incorporation and metabolism of (n-3) and (n-6) polyunsaturated fatty acids in phospholipid classes in cultured turbot (Scophthalmus maximus) cell. Fish Physiol. Biochem., 8, 251-260 (1990).

15) D. R. Tocher: Incorporation and metabolism of (n-3) and (n-6) polyunsaturated fatty acids in phospholipid classes in cultured rainbow trout (Salmo gairdneri) cell. Fish Physiol. Biochem., 8, 239- 
$249(1990)$.

16) W. M. Koven, A. Tandler, D. Sklan, and G. W. Kissil: The association of eicosapentaenoic and docosahexaenoic acids in the main phospholipids of defferent-age Sparus aurata larvae with growth. Aquaculture, 116, 71-82 (1993).

17) J. C. Navarro, R. S. Batty, M. V. Bell, and J. R. Sargent: Effects of two Artemia with different contents of polyunsaturated fatty acids on the lipid composition of larvae of Atlantic herring (Clupea hareaus). J. Fish Biol., 43, 503-515 (1993).

18) M. V. Bell and J. R. Dick: Molecular species composition of the major phospholipids from muscle, liver, retina and brain of cod (Gadus morhua). Lipids, 26, 565-573 (1991).

19) A. Kanazawa: Nutritional mechanisms involved in the occurrence of abnormal pigmentation in hatchery-reared flatfish. $J$. World Aquacult. Soc., 24, 162-166 (1993). 